\title{
Laser-assisted machining process simulation for precision mould/die manufacturing
}

\author{
Quanren Zeng and Yi Qin ${ }^{\mathrm{a}}$ \\ Dept. of Design, Manufacture \& Engineering Management, University of Strathclyde, Glasgow \\ G1 1XQ, UK
}

\begin{abstract}
Laser-assisted machining (LAM) is a kind of thermally assisted manufacturing process which preheats workpiece material with a highly-localized laser beam and then is followed by a conventional machining operation. It could greatly improve the machinability and gives better machining quality, especially suitable for hard-to-cut materials such as superalloys, tool steels. For manufacturing the high-precision moulds/dies that could fabricate micro and precision components, the thermal assistance at the local cutting zone, will help to lower the cutting force and consequently improve the internal surface quality of the machined moulds/dies. In this paper, a numerical study of the laser-assisted cutting of plastic mould steel NAK80 is reported. The simulation of LAM of NAK80 is realized by combining two procedures: simulation of moving laser heat source applied on the local surface of workpiece which causes the corresponding temperature field arise and material soften, and simulation of the subsequent cutting processes. This research will offer the die/mould manufacturers a more efficient planning tool for the fabrication of the micro, precision dies/moulds of high surface quality, and hence, for forming the high-quality micro components as well as for longer die/mould life.
\end{abstract}

\section{Introduction}

Nowadays, rubber and plastic products have widely used in automobile, naval architecture, aerospace industry and household appliance due to their superior features, such as resistances to chemicals and corrosion, low density and light weight, easy to manufacture and high cost-efficiency etc. They are becoming more and more significant in the engineering field and have increasingly substituted metallic components in many industrial applications. At the meanwhile, micro sized or structured products with high surface precision have attracted many attentions both in academia and industry. The requirement for the basic size accuracy, dimensional tolerance and surface quality of the micro formed rubber or plastic components are demanding and rigorous.

High-precision mould/die is one of the most important forming tools for fabricating micro plastic components in mass production. The interior surface quality and integrity of the cavity of the plastic injection mould is critical to the external appearance and dimensional accuracy of the final products.

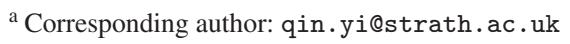

This is an Open Access article distributed under the terms of the Creative Commons Attribution License 4.0, which permits unrestricted use, distribution, and reproduction in any medium, provided the original work is properly cited. 


\section{MATEC Web of Conferences}

Machining processes, such as hard turning, boring, grinding and polishing, are commonly-used means to improve the surface finish of the mould cavity. Due to high requirement of interior surface quality for the machined mould cavity, the material that making a high-precision mould is usually required to be able to offer sufficient strength and hardness along with ideal machinability. NAK80 is a kind of prehardened tool steel with high performance and high machining precision. It has uniform microstructure and hardness (around $40 \mathrm{HRC}$ ) between its surface and interior and is suitable for mirror polishing that needed for manufacturing a thermoplastics mould. These superior properties mean it needs not any stress relief process even after some heavy-duty machining processes. NAK80 is also highly weldable because its heat-affected-zone will become softer again and could restore to the original hardness 40HRC by reageing hardening. Although the hardness of NAK80 is not as high as ceramic or superalloys, it is still regarded as a kind of difficult-to-machine material due to lath martensite and hard particulates $\left(\mathrm{Ni}_{3} \mathrm{Al}\right.$ or $\varepsilon-\mathrm{Cu}$ ) dispersed within bulk, which gives it relatively high material strength and toughness. The main application of NAK80 includes plastic moulds, rubber moulds, jigs \& fixtures, press dies and so on.

Laser-assisted machining (LAM) is a thermally enhanced machining process which takes advantage of reducing of material strength by means of increasing temperature of the workpiece to be cut. LAM is especially suitable for dealing with difficult-to-machine materials by preheating and softening the workpiece surface before the subsequent conventional material removal processes. Due to the importance of temperature distribution near the local cutting zone during LAM, a lot of efforts have been made to simulate the temperature distribution caused by laser radiation along with subsequent cutting operations on various difficult-to-machine materials [1-3]. These thermal models can help to identify the effect of operational parameters (both laser-related processing parameters and machiningrelated processing parameters) on the temperature distribution at the cutting zone and is reversely able to provide guidelines on parameter selection for optimizing the machining process.

The high-precision micro mould/die which is made of NAK80 is a tool for producing precision surfaces of micro non-metallic products. As abovementioned, its working surfaces need to be well machined with quite high dimensional accuracy and surface quality along with complex micro structured features. Laser assisted machining is adopted to machine the mould/die with high surface quality and machining efficiency. In this paper, the max cutting forces and the max temperatures of machining NAK80 are analysed based on specific tool geometry, cutting speed and depth of cut. The results obtained with and without laser assistance are also compared and discussed.

\section{LAM characteristics \& its temperature distribution calculation}

During the process of LAM, the local heating of workpiecee by an external laser heat source will soften and may change the workpiece material's deformation behaviour from brittle to ductile. This enables the difficult-to-machine materials more easily to be removed [4, 5]. As shown in Fig. 1, the advantages of laser beam over the other heat sources are its controllable spot size and high power density, which lead to rapidly-elevated temperature and create a large thermal gradient through thickness and distance near the irradiated spot. It is notable that only the specific location to-be-removed is effectively and intensively heated which ensures a narrow heat affected zone and minimum thermal distortion without affecting the integrity of the machined subsurface.

\subsection{Temperature field near the location of LAM}

In LAM, the laser beam energy is absorbed by the workpiece surface and converted to thermal energy which causes temperature rise on the specific location of workpiece surface. As the deformation behaviour of workpiece is strongly dependent on its temperature, it is essential to know the temperature distribution from the surface to the subsurface and even up to the cutting edge. Actually, laser power, laser spot diameter, preheat time, laser-tool lead are the main operational parameters for laser assisted 


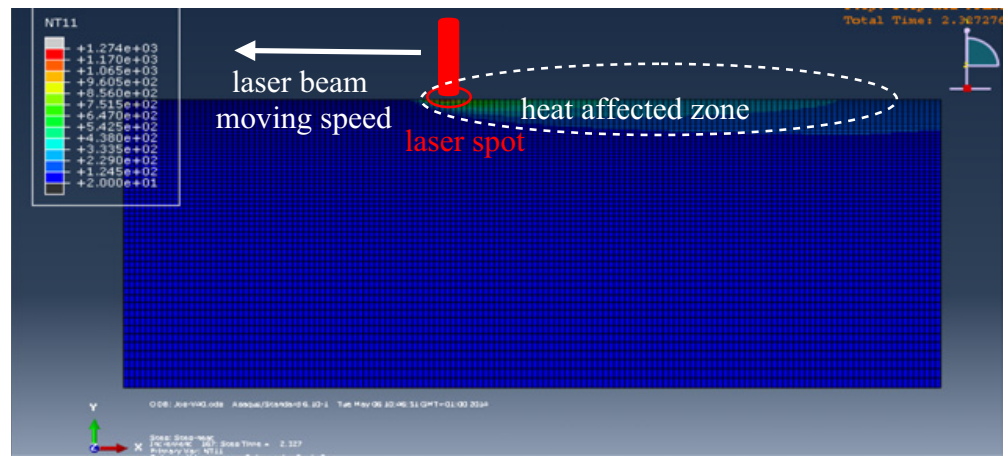

Figure 1. Simulation of moving laser heat source on workpiece without material removal.

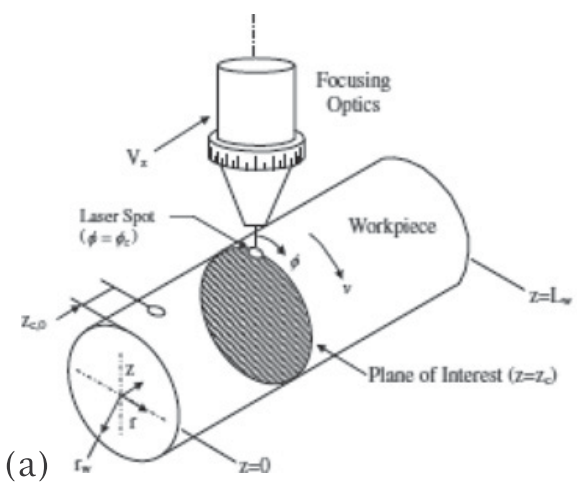

(b)

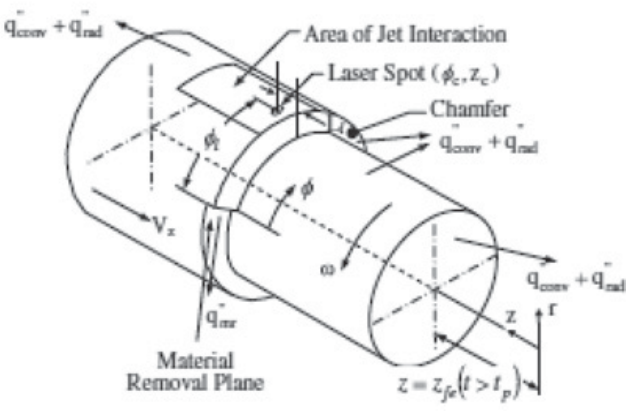

Figure 2. Coordinate system for the rotating workpiece during (a) laser heating without material removal and (b) LAM with material removal $[1,2]$.

machining process as well as the thermal absorption rate. The thermal response of the rotating opaque cylindrical workpiece subjected to laser radiation with and without materials removal process has been analysed with a transient, three-dimensional heat transfer model by Rozzi et al. [1,2]. The model geometries are shown in Fig. 2.

The governing equation for transient heat transfer in a rotating cylinder in a cylindrical coordinate system could be expressed as $[1,2]$ :

$$
\underbrace{\frac{1}{r} \frac{\partial}{\partial r}\left(k r \frac{\partial T}{\partial r}\right)+\frac{1}{r^{2}} \frac{\partial}{\partial \phi}\left(k \frac{\partial T}{\partial \phi}\right)+\frac{\partial}{\partial z}\left(k \frac{\partial T}{\partial z}\right)}_{\text {Conduction }}+q^{\prime \prime \prime}=\underbrace{\rho c_{p} \omega \frac{\partial T}{\partial \phi}+\rho c_{p} V_{z} \frac{\partial T}{\partial z}}_{\text {Advection }}+\underbrace{\rho c_{p} \frac{\partial T}{\partial t}}_{\text {Strorage }}
$$

where, $k$ is the thermal conductivity; $\rho$ is the material density; $c_{p}$ is the specific heat; $\omega$ is the workpiece rotation speed; $V_{z}$ is the feed speed and $q^{\prime \prime \prime}$ is the volumetric heat generation due to the cutting operation, which includes the heat generated due to the friction between the tool's flank face and workpiece and the heat generated due to plastic deformation $q_{p l}^{\prime \prime \prime}$ at shear zone. Because of a long time delay after cutting for one revolution and its small magnitude, the heat caused by flank wear has a negligible effect on the workpiece temperature distribution. The heat generated due to the plastic deformation could be 
Table 1. Mechanical and physical properties of NAK80[6].

\begin{tabular}{|c|c|c|c|}
\hline Material properties & & Material properties & \\
\hline Tensile Strength, $\sigma_{b}(\mathrm{MPa})$ & 1264.5 & \multirow{3}{*}{$\begin{array}{l}\text { Coefficient of Thermal } \\
\text { Expansion, } \\
e\left(\times 10^{-6} \mathrm{~m} / \mathrm{m} /{ }^{\circ} \mathrm{C}\right)\end{array}$} & $11.34\left(20^{\circ} \mathrm{C}\right.$ to $\left.100^{\circ} \mathrm{C}\right)$ \\
\hline Yield Strength, $\sigma_{s}(\mathrm{MPa})$ & 1017.7 & & $12.6\left(20^{\circ} \mathrm{C}\right.$ to $\left.200^{\circ} \mathrm{C}\right)$ \\
\hline Reduction of Area, $\psi$ & $41.9 \%$ & & $13.5\left(20^{\circ} \mathrm{C}\right.$ to $\left.300^{\circ} \mathrm{C}\right)$ \\
\hline Elongation, $\varphi$ & $16.1 \%$ & \multirow{2}{*}{$\begin{array}{l}\text { Coefficient of Thermal } \\
\text { Conductivity, } \\
k\left(\mathrm{~W} \mathrm{~m}^{-1} \mathrm{~K}^{-1}\right)\end{array}$} & $38.94 @ 20^{\circ} \mathrm{C}$ \\
\hline Modulus of Elasticity, $E$ (Mpa) & 206.8 & & $\begin{array}{l}41.33 @ 93.3^{\circ} \mathrm{C} \\
41.87 @ 200^{\circ} \mathrm{C} \\
42.19 @ 204^{\circ} \mathrm{C} \\
42.71 @ 300^{\circ} \mathrm{C}\end{array}$ \\
\hline Specific heat, $c_{p}\left(\mathrm{~J} /\left(\mathrm{kg} .{ }^{\circ} \mathrm{C}\right)\right)$ & 526.3 & Density, $\rho\left(\mathrm{kg} / \mathrm{m}^{3}\right)$ & 7800 \\
\hline$T_{m}\left({ }^{\circ} \mathrm{C}\right)$ & 1515 & & \\
\hline
\end{tabular}

calculated as $[1,2]$ :

$$
\left\{\begin{array}{lr}
q_{p l}^{\prime \prime \prime}=0 & \text { without material removal } \\
q_{p l}^{\prime \prime \prime}=\frac{0.85\left(F_{c} \cdot \bar{V}_{w}-F_{c t} \cdot V_{c h i p}\right) P_{C O_{2}}^{0.85}}{\left(d L_{f}^{2} / 10\right)} & \text { with material removal }
\end{array}\right.
$$

where $F_{c}$ is the main cutting force; $\bar{V}_{w}$ is the average workpiece velocity perpendicular to the cutting tool over the depth of cut; $F_{c t}$ is the friction force; $V_{c h i p}$ is the average chip velocity on the tool rake face; $d$ is the depth of cut and $L_{f}$ is the tool feed.

\section{Simulations and design}

\subsection{Material properties and constitutive model}

The workpiece material used in the conventional cutting and LAM simulation is NAK80 plastic model steel. The major chemical compositions of the NAK80 are as follows: $\mathrm{C}, 0.15 \% ; \mathrm{Si}, 0.3 \% ; \mathrm{Mn}, 1.5 \%$; Ni, $3.0 \% ; \mathrm{Al}, 1.0 \% ; \mathrm{Cu}, 1.0 \% ; \mathrm{Fe}, 93.05 \%$. The main mechanical and physical properties such as thermal conductivity, specific heat and coefficient of thermal expansion of NAK80 are shown in Table 1.

Considering the thermal elasto-plastic characteristics, the Johnson-Cook constitutive model is adopted to simulate the material flow state during cutting. The functional expression of Johnson-Cook model is

$$
\sigma=\left(A+B\left(\varepsilon^{p}\right)^{n}\right)\left[1+C \ln \left(\frac{\dot{\varepsilon}^{p}}{\dot{\varepsilon}_{0}}\right)\right] \times\left[1-\left(\frac{T-T_{r}}{T_{m}-T_{r}}\right)^{m}\right] .
$$

In which $\varepsilon^{p}$ is the equivalent plastic strain; $\dot{\varepsilon}^{p}$ is the plastic strain rate; $\dot{\varepsilon}_{0}$ is initial plastic strain rate; $\mathrm{T}$ is the current work temperature; $T_{m}$ is the melting point of the material and $T_{r}$ is the reference temperature. $A, B, C, n$ and $m$ are material parameters to be determined. $A$ is the yield stress at temperatures below $T_{r} ; \dot{\varepsilon}_{0}$ and $\mathrm{C}$ are usually measured at or below the reference temperature. In this research, the material parameters selected for simulation are [7]: $A=1257 \mathrm{MPa}, B=982.4 \mathrm{MPa}, n=0.59, m=1.088$. $\dot{\varepsilon}_{0}=10^{-2}$.

\subsection{Boundary conditions and assumptions}

The tool geometry and cutting parameters are also influential factors for machined surface quality and integrity of high-precision mould. The common tool geometry parameters that matter the machined surface quality are tool nose radius, rake angle, clearance angle. The operational parameters that matter could be categorized into laser-related processing parameters and machining-related processing 

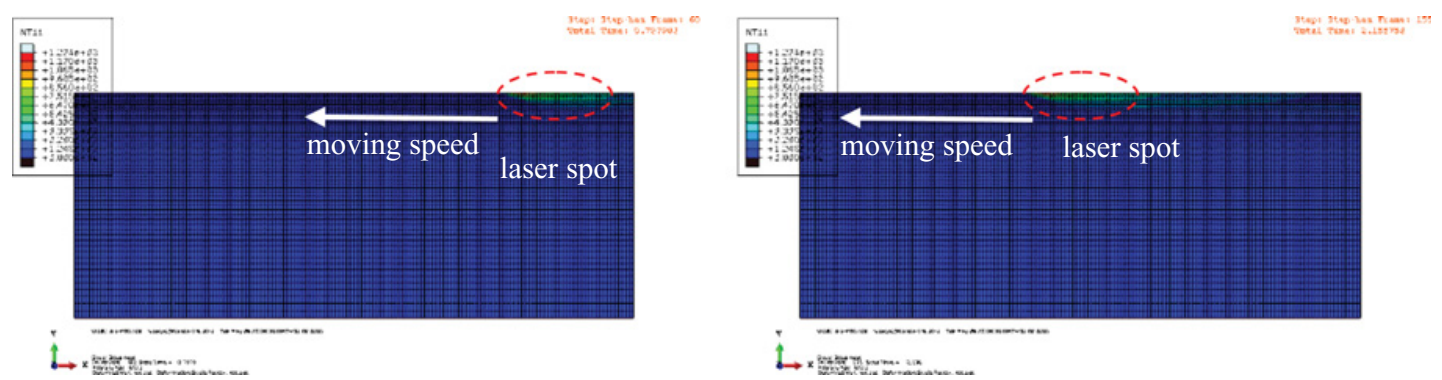

Figure 3. Simulation of moving temperature field of laser on NAK 80 workpiece $(P=2000 \mathrm{~W}, v=25 \mathrm{~mm} / \mathrm{s})$.

parameters. In this research, the tool for cutting simulation is assumed to be rigid with rake angle $\gamma=$ $10^{\circ}$, clearance angle $\alpha=6^{\circ}$, tool nose radius $R_{\text {tip }}=0.02 \mathrm{~mm}$. Cutting speed $v_{s}=25 \mathrm{~mm} / \mathrm{s}$, depth of cut $a_{p}=0.1 \mathrm{~mm}$, laser power $P=1200 \mathrm{~W}$ or $2000 \mathrm{~W}$, laser moving velocity $v_{z}=25 \mathrm{~mm} / \mathrm{s}$. Workpiece is simplified to be a rectangular block with a size dimension $150 \mathrm{~mm} \times 60 \mathrm{~mm}$. The bottom and the left side of the workpiece are applied with fixed boundary condition. Workpiece material NAK80 is assumed to be isotropic and follows Johnson-cook plastic criterion. No material phase transformation under machined surface is considered. The laser power is assumed to be completely absorbed and transferred to thermal energy into the workpiece.

Accurate description of thermal energy distribution of the laser beam delivered on the workpiece surface is critical to the LAM process. In this paper, heat flux coming from a laser beam is assumed to follow Gaussian distribution, and the final LAM process is simulated in terms of two steps:

(1) Simulation of the moving temperature field caused only by the corresponding moving laser beam;

(2) Simulation of mechanical cutting which considers the temperature field due to laser preheating by importing the temperature file at the corresponding time increments generated in Step 1.

\section{Results and discussions}

By specifying proper boundary conditions, the moving temperature distribution as a result of laser radiation was simulated. In Fig. 3, the temperature distribution is moving with the laser spot with specific laser speed $v=25 \mathrm{~mm} / \mathrm{s}$. The laser power is $P=2000 \mathrm{~W}$ and the corresponding laser heat flux follows Gaussian distribution. The materials properties of workpiece are partially temperature-dependant as shown in Table 1. The final max temperature in this simulation is around $1270^{\circ} \mathrm{C}$ at the local position near the laser spot; the max thickness of heat affected zone (HAZ) is around $7.5 \mathrm{~mm}$.

Figure 4(a) \& (b) give the simulation of temperature variation from conventional cutting and the max temperature near the cutting zone in the tool/workpiece system is around $863{ }^{\circ} \mathrm{C}$; while Fig. 4 (c) \& (d) gives the simulation of temperature variation from laser assisted machining which has considered the effect of laser preheating, the max temperature near the cutting zone is only $755^{\circ} \mathrm{C}$ which is lower than conventional cutting only. It is because the external laser preheating leads to high temperatures at the shear zone which results in a reduction in the shear flow stress of the workpiece and lowers the workpiece yield strength. Therefore, the heat generation due to the mechanically-cutting caused plastic deformation in the shear zone for LAM is largely reduced when compared with that produced during conventional cutting process, which finally makes the max temperature during LAM lower than that during conventional cutting. Figure 5 compared the max stresses and cutting forces of conventional cutting and LAM. The max cutting force and stress caused by LAM are $1290 \mathrm{MPa}$ and $308 \mathrm{~N}$ which are obviously lower than those from conventional cutting. It is also because of the less plastic deformation being produced within the shear zone during LAM. 


\section{MATEC Web of Conferences}

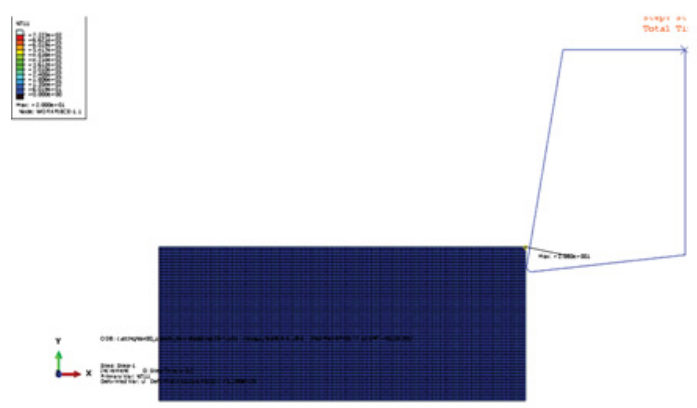

(a) Conventional cutting, $v=25 \mathrm{~mm} / \mathrm{s}, t=0$ )

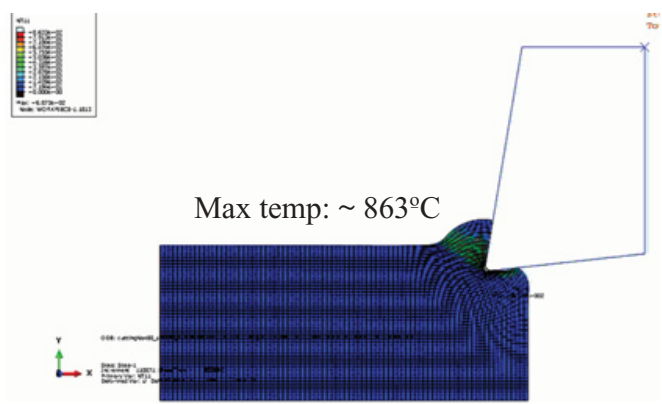

(b) Conventional cutting, $v=25 \mathrm{~mm} / \mathrm{s}, t=0.6 \mathrm{~s}$ )

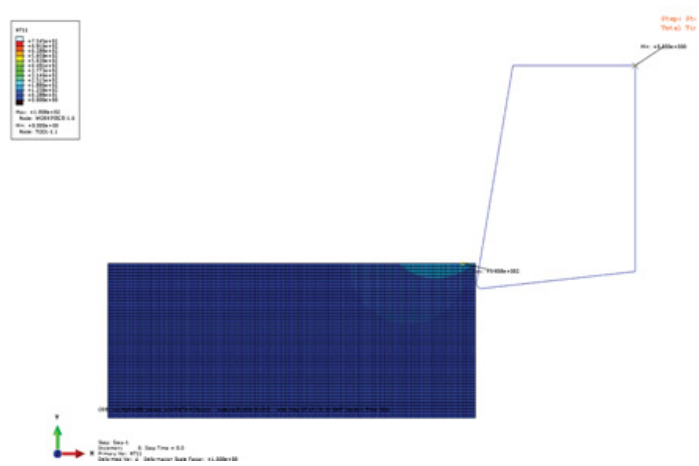

(c) $\operatorname{LAM}(P=1200 \mathrm{~W}, v=25 \mathrm{~mm} / \mathrm{s}, t=0)$

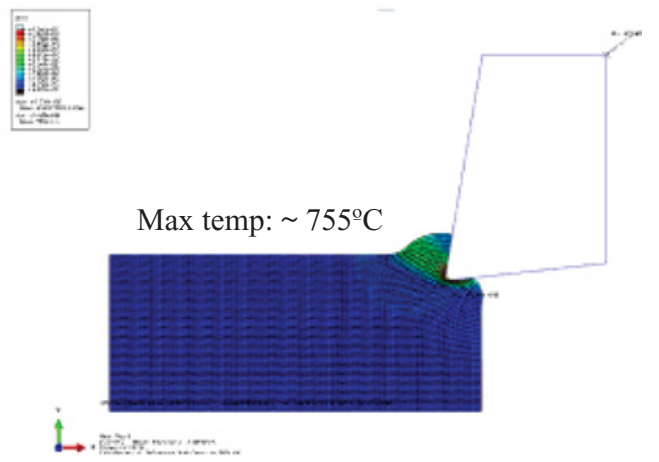

(d) $\operatorname{LAM}(P=1200 \mathrm{~W}, v=25 \mathrm{~mm} / \mathrm{s}, t=0.6 \mathrm{~s})$

Figure 4. Simulation of temperature variation during (a)\&(b) conventional cutting without laser preheating and (c)\&(d) LAM for NAK80.

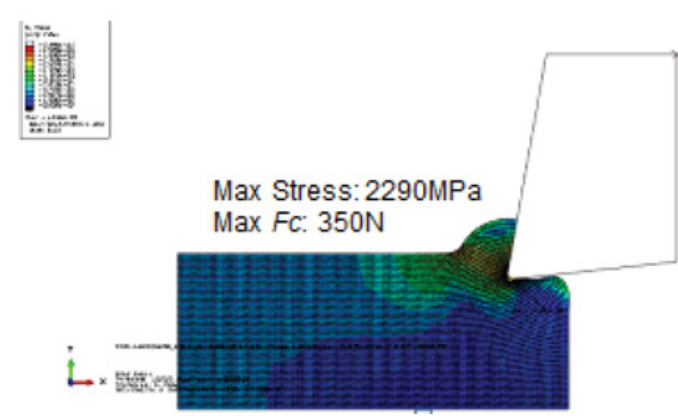

(a) stress variation of conventional cutting

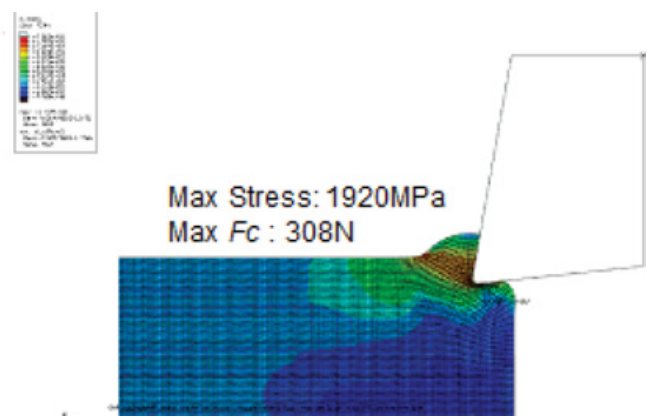

(b) stress variation of LAM

Figure 5. Simulation of stress distribution during (a) conventional cutting without laser preheating and (b) LAM for NAK80 $(P=1200 \mathrm{~W}, v=25 \mathrm{~mm} / \mathrm{s})$.

\section{Conclusions}

In this paper, a 2D FE model has been implemented to simulate LAM of plastic mould steel NAK80. The max cutting temperature, max cutting forces and corresponding stress during the LAM are derived and compared with the conventional cutting process. The results of LAM which is different from those of conventional cutting indicated that LAM could greatly improve the cutting condition and low the corresponding max cutting force, stress and max temperature, which also means the corresponding 


\section{ICNFT 2015}

machined surface roughness and efficiency are also meliorated. This study offers the die/mould manufacturers an efficient planning tool for the fabrication of the micro, precision dies/moulds of high surface quality, and hence, for forming the high-quality micro components as well as for longer die/mould life.

\section{References}

[1] J.C. Rozzi, F.E. Pfefferkorn, F.P. Incropera, Y.C. Shin, Int. J. Heat Mass Transfer, 43, 1409 (2000)

[2] J.C. Rozzi, F.P. Incropera, Y.C. Shin, Int. J. Heat Mass Transfer, 43, 1425 (2000)

[3] F.E. Pfefferkorn, F.P. Incropera, Y.C. Shin, Int. J. Heat Mass Transfer, 48, 1999 (2005)

[4] Y. Tian, B. Wu, M. Anderson, Y.C. Shin, ASME J. Manuf. Sci. Eng., 130, 031013-1 (2006)

[5] C.R. Dandekar, Y.C. Shin, J. Mat. Pro. Tec. 213153 (2013)

[6] http://matweb.com/search/DataSheet.aspx?MatGUID=d1dbcd9b46a44137a7aa008fd fca9f54\&ckck $=1$

[7] T. Fu, W. Liu, J. Zhao, Proceeding of 5th ICMTMA2013, 135, 544 (2013) 